\title{
Arthur, J. and Davies, I. (Eds.) (2010). The Routledge Education Studies Reader (2010). New York: Routledge. 374 p., ISBN 978-041-548-236-3.
}

Reviewed by NikA ŠUšTERIČ

"We wanted something that would stimulate this varied group of students to continue asking questions and developing provisional answers about some of the major issues that affect and characterise education."

James Arthur and Ian Davies

The Routledge Education Studies Reader 2010, 1

For the last 15 years or so, the field of education has gained new strength, as is persuasively testified to by the renewed lively interest in education from both politicians and the broader public. The development and establishment of new study programmes, such as education studies, education policy studies, etc., and the increased publication of books and readers whose primary aim is to provide an introduction to these fields for students of such programmes, are further signs of this invigoration. Amongst the latter is The Routledge Education Studies Reader, edited by James Arthur and Ian Davies, accompanied by The Routledge Education Studies Textbook, edited by the same authors, both of whom are experts in the field of education and/or education studies.

According to the editors, the Reader's purpose is not to be exclusive, and this goal is successfully achieved; nevertheless, it first and foremost targets students of education studies who have completed at least one year of studies and are thus probably already acquainted with some of the field's "classics".

Examining the structure of the Reader, it is obvious that the editors bore in mind their target readership. It is transparently divided into three major sections, which will help readers to organise their thoughts on the diverse issues of education studies.

The first section, entitled Foundations of Education, is an adequate introduction to the other sections and to the texts in the Reader, as well as to the study of the field of education itself. The first text, by G. McCulloh, engages with the nature of education studies, thus providing a meaningful passage to the following texts. The next subchapters furnish the reader with an insight into the various points of approach to the questions of education; namely, the perspectives of those disciplines that are crucial for understanding education and its processes, the so-called "foundation disciplines" - history, philosophy, 
psychology and sociology. Although all of the texts in the Reader are accessible to all types of readers, even to "newcomers", some of them, especially those in Section 1, require more effort. However, the understanding of these texts is essential for a more appropriate conceptualisation and elucidation of the other texts. One such example is the chapter Learning: Meaning, Language and Culture, originally published in the book Making Sense of Education: An Introduction to the Philosophy and Theory of Education by D. Carr. The text discusses the concept of understanding, while also pointing out the effects and consequences that different conceptions of the elements of education position as the processes and goals of education, as ultimately it is these conceptions that underlie specific education policies. If Carr's reconsiderations of the given subjects appear to be somewhat difficult or too abstract for a young reader, it is very likely that the meaning of these approaches will become clearer after reading the text by Brian Simon. In his article The History of Education: Its Importance for Understanding, Simon sets out an argument about the meaning of knowledge of the history of education. One of the crucial factors that enables theorists and practitioners to understand and identify the lines of force crossing the field of education is knowledge of the development and historical transformations of education. Through this moment, Simon helps us to realise the changes that have crossed education and the issues that affect it, as well as the fact that education does not rest peacefully on its islands of autonomy, but is rather the site of numerous struggles. And these problems and phenomena, as the reader will probably realise, can only be grasped and conceptualised with the complex means of foundation disciplines. In this way, the Reader, with the texts selected, encourages readers to critically investigate the everyday self-evidences that have managed to find their way into the very formation of education policies.

In the second part, entitled Contexts: Making Education Work, we can find texts by various authors, both classical and contemporary, discussing particular elements of, or dilemmas arising in, the field of education. The texts cover subjects such as education policies, curriculum, pedagogy, faith-based education, private education, etc. One of the Reader's advantages is that it manages to introduce specific problems from different points of view and theoretical positions, thus making it less biased. This offers a certain broadness to the reader, but perhaps it could also be a trap for those who have not yet acquired enough knowledge of the area to make sense of, and critically reflect upon, the selected texts.

In addition, the section provides readers with articles that debate relatively unexplored educational phenomena of today. A representative of such debates is the text by R. Mason and F. Rennie, which explores various online 
resources and communication tools that can represent a significant contribution to education. Also published in this section is an extract from J. Dewey's famous Democracy and Education - the part of his work entitled Education as a Social Function - and a section from J. Holt's book, How Children Fail.

Last but not least, the third section, entitled Doing Education Studies, covers the area of research in the field of education. To quote the editors: "Research is not conducted in tranquil settings by intellectuals who seek some sort of lofty disinterestedness." (ibid. p. 2). The area of research is no exception when it comes to the clash of different ideas and interests. It faces serious conflicts regarding the conceptualisation and methods appropriate for researching the field of education. Bearing this in mind, the three selected texts debating this matter are more than suitable. The first text, by P. Davies, entitled What is evidence-based education?, speaks of the concept referred to in the title and its contribution to improving educational practice, thus pointing out the effect and importance of quality research conducted in the field. By highlighting these aspects, the author successfully distances research activity from the aforementioned academic disinterestedness and exposes the potential for the everyday practical use of research results and the conditions of such use. N.L. Gage's text is yet another piece that is in accordance with the editors' wish for the Reader to be a springboard for further questioning and exploration. As the title itself suggests, Gage points out a peculiar obviousness to the results of social and educational research, which can have a significant influence on the motivation of research in these fields. However, Gage shows that the feeling of obviousness is certainly not automatically trustworthy.

The choice of texts and authors, as well as the structure of the Reader, demonstrate the fact that the editors know how to avoid losing sight of the purpose of the book. The short introductions that appear before each text turn out to be quite handy for beginners. Prior to each text there is a short description of the author and his or her works and fields of interest, as well as a few sentences about the text that follows. This gives young readers an opportunity to gain a quick insight into the text, as well as facilitating selective reading for those who already have some mileage in this sort of literature. This part is followed by a short segment entitled Key Questions, a variant of a feature that is becoming standard practice in this sort of reading material. In view of the editors' claim that they have "shaped the Readings in ways that are intended to encourage critical reading" (ibid., p. 3), and taking into account the target population of the Reader, i.e., students who have already come to terms with the field of education to some extent but are still involved in a study programme, as well as the assumption that reading strategies are something to be learned, this 
short fragment represents a welcome aid to young readers who are still becoming accustomed to critically reflecting on what they have read. It consists of a few questions that, although perhaps a bit general in places, can still be seen as a support for young readers - something that they will gradually dismiss as they learn to consider similar questions on their own. The next part is entitled Further Reading and directs readers to other literature concerning the topic by relevant author(s), an addition that is thus quite convenient for a varied group of readers. Just before the beginning of the text there is a note that links the given reading with corresponding chapters in the Textbook.

In summary, the Reader meets its goals and purposes. As a whole, it is indeed student-friendly and will surely attract the attention of more experienced readers or teachers, while there is no doubt that the Reader is one of only a few works seeking to introduce the field of education to beginners. For many readers, it just may be an effective gateway to, and insight into, education studies. Its systematic way of introducing the basic educational issues, and its perspectives in discussing them, might come in even more handy for students who are getting to know this field in countries that have not yet established thorough education studies programmes. Even a quick overview of the contents provides readers with a rough idea of the complexity and interdisciplinarity of the field. The texts are well chosen and cover a wide range of subjects important for education and its processes. Among them we can find texts from some classical names, such as J. Dewey, J. Holt and J. Bruner, as well as from some well known contemporary names, such as B. Simon, D. Carr, R. Peters and many others. The Routledge Education Studies Reader definitely offers a good first (or second) taste - a taste that might just encourage many readers to ask for more. 